\title{
Novel Multifunctional Porous Liquid Composite for Recyclable Sequestration, Storage and In-situ Catalytic Conversion of Carbon Dioxide
}

Archita Bhattacharjee, Raj Kumar, and Kamendra P. Sharma*

\author{
Dr. A. Bhattacharjee, R. Kumar and Prof. K. P. Sharma* \\ Department of Chemistry, IIT Bombay, Powai, India \\ E-mail: k.sharma@,chem.iitb.ac.in
}

Keywords: Porous liquid composite, mesoporous liquid, hollow silica nanorods, $\mathrm{CO}_{2}$ capture, $\mathrm{CO}_{2}$ catalytic conversion

Abstract: Permanent pores combined with fluidity renders flow processability to porous liquids otherwise not seen in porous solids. Although, sequestration of different gases has recently been shown in porous liquids, there is still adearth of studies for deploying in-situ chemical reactionsto convert adsorbed gases into utility chemicals in this phase. Here, a facile method for the design and development of a new class of solvent-less porous liquid composite which, as shown for the first time, can catalyze the conversion of adsorbed gaseous molecules into industrially relevant product, is shown. The recyclable porous liquid composite comprising polymer-surfactant modified hollow silica nanorods and carbonic anhydrase enzyme not only sequesters $\left(5.5 \mathrm{cc} \mathrm{g}^{-1}\right.$ at $273 \mathrm{~K}$ and $\left.1 \mathrm{~atm}\right)$ and stores $\mathrm{CO}_{2}$, but is also capable of driving an in-situ enzymatic reaction for hydration of $\mathrm{CO}_{2}$ to $\mathrm{HCO}_{3}^{-}$ion, subsequently converting it $\mathrm{CaCO}_{3}$ due to reaction with pre-dissolved $\mathrm{Ca}^{2+}$. Light and electron microscopy combined with x-ray diffraction reveals the nucleation and growth of calcite and aragonite crystals. Moreover, the liquid-like property of the porous composite material can be harnessed by executing the same reaction via diffusion ofcomplimentary $\mathrm{Ca}^{2+}$ and $\mathrm{HCO}_{3}{ }^{-}$ions through different compartments separated by an interfacial channel. 
The escalating environmental degradation due to extensive greenhouse gas emissions from anthropogenic sources is a major problem of the $21^{\text {st }}$ century. Particularly, the rise in atmospheric $\mathrm{CO}_{2}$ levels has led to substantial global warming. International energy agency (IEA) report suggests that the present $\mathrm{CO}_{2}$ emissions are $\approx 37$ Gigatonnes/year, ${ }^{[1]}$ and going by similar emission trends, in few years' time this could lead to catastrophic environmental changes. These changes can only be prevented if we could limit the global warming to a maximum of $2{ }^{\circ} \mathrm{C} .^{[1]}$ Latest studies show that this can be achieved by following the IEA projection for storage of 6000 million tonnes of $\mathrm{CO}_{2}$ per year $\left(\mathrm{MtCO}_{2} /\right.$ year $)$ by $2050 .{ }^{1}$ Carbon capture and storage at the end of 2018 has been projected to be $\approx 4-5 \mathrm{MtCO}_{2} /$ year, much lower than the proposed storage guidelines. ${ }^{2}$ The use of solid porous materials for gas storage proves to be a potential technology to mitigate this problem. Therefore, in recent years, various classes of porous solids such as carbon, ${ }^{3}$ metal-organic frameworks, ${ }^{4}$ amine modified silica, ${ }^{5}$ etc. have been developed for $\mathrm{CO}_{2}$ capture and storage. Further, it can be envisaged to reduce $\mathrm{CO}_{2}$ by post-capture utilization/conversion to utility chemicals, however, the intrinsic solid nature of porous solids remains a constraint in their implementation for continuous flow industrial processes.

Liquids based on molecular amines, can be circulated easily in existing industrial plants and are thus used for the post-combustion chemisorption of $\mathrm{CO}_{2}$, much in contrast to solid adsorbents. ${ }^{6}$ However, separation of chemisorbed $\mathrm{CO}_{2}$ from the amines is also associated with higher energy penalties, ${ }^{7}$ and therefore, impose severe limitations; total thermal energy consumption for regeneration of $\mathrm{CO}_{2}$ adsorbent from monoethanol amine (MEA) adsorbate is $4.56 \mathrm{GJ} /$ tonnes of $\mathrm{CO}_{2}{ }^{8}$ Further, all conventional liquids possess transient and extrinsic micro-pores and hence cannot be used for gas sequestration. Hence, a requirement for different type of porous liquids which possess permanent and intrinsic porosity was envisaged in 2007 , and since has been a hot topic in the scientific community. ${ }^{9-}$ 
${ }^{15}$ Microporous liquids with permanent porosity of $\approx 1-3 \AA$ were shown for the first time by dissolving crown-ether organic cages in sterically hindered solvent. ${ }^{16}$ Metal organic frameworks and zeolites with microporous frameworks have also been employed as host molecules in bulky ionic liquid medium to form another class of microporous liquids. ${ }^{17-22}$ Mesoporous liquids (pore size $>2 \mathrm{~nm}$ ) comprising hollow silica particles or carbon surface engineered with polymers have been recently shown to trap gaseous adsorbents. ${ }^{23-26}$ However, all the above examples demonstrate porous liquids that can sequester different types of gases, but, very few of them have been utilized for the deployment of a chemical reaction for converting the adsorbed gases to utility chemicals. The major challenge is finding a reaction suitable sterically hindered solvent, and also ensuring that the catalytic component as well as the product does not occlude the pores. This motivated us towards developing a benign and uncomplicated method for fabrication of a different class of multifunctional porous liquid which not only reversibly sequesters, stores, but also can be used to deploy chemical reaction for converting the adsorbed gases to non-hazardous products, thus, offering significant technological advantages by coupling properties of fluidity, permanent porosity with catalysis.

Variety of methods have been developed for the catalytic conversion of $\mathrm{CO}_{2}$, however, green, biomimetic and economical route from carbonic anhydrase (a zinc metalloenzyme) is one of the most promising of them. ${ }^{27,28}$ However, native enzymes in their aqueous solution are highly sensitive towards $\mathrm{pH}$ and higher temperature which restricts its industrial usage in non-optimum conditions. Recently, solvent-free protein liquids (with residual water $\approx 1-2 \%$ ) comprising stoichiometric protein-polymer surfactants bioconjugates obtained by surface engineering of proteins have been shown. ${ }^{29-31}$ Proteins in these bioconjugates exhibit a near native secondary structure, and an intact functionality, even at $150{ }^{\circ} \mathrm{C}$. Using a similar approach, carbonic anhydrase enzyme can also be stabilized to act as 
a catalyst for $\mathrm{CO}_{2}$ conversion. Further, in conjunction with the catalytic properties of solventless bioconjugated carbonic anhydrase, fluid-like and gas adsorption properties of a mesoporous liquid (comprising anisotropic hollow silica nanorods ${ }^{32}$ covalently grafted with organosilane followed by the electrostatic coupling with anionic polymer-surfactant) can be deployed, to form a solvent-less porous liquid composite. The nanorods percolate at lower concentrations as compared to spheres, thereby providing tuneability in viscosity of the system at room temperature. Here, we show the design and development of a new class of solvent-less porous liquid which combines catalytic activity of bioconjugated carbonic anhydrase with the hollow cores of silica nanorods, to reversibly sequester, store (below the glass transition temperature of material), and also catalytically convert carbon dioxide into industrially relevant calcium carbonate. The process of calcium carbonate formation was analysed using a combination of polarised optical microscopy, TEM, SEM and XRD. Such a chemical transformation alters the $\mathrm{pH}$ and can be manually visualized by incorporating a $\mathrm{pH}$ indicator dye which changes colour of the entire composite liquid. Further, the importance of liquid like nature of this composite is shown by the diffusivity and reaction of complementary ions across different compartment connected by a non-reactive channel.

Design and development of composite porous liquid (PoLi-bCA) comprising two different core-shell conjugates i.e. hollow silica nanorods-polymer surfactant based porous liquid (PoLi), and carbonic anhydrase enzyme-polymer surfactant (bCA), was done by dispersing individual conjugates (see methods in SI for the synthesis on individual core-shell conjugates) in a $10 \mathrm{mM}$ phosphate buffer $(\mathrm{pH}=5.8)$ to provide nanorod to enzyme number ratio as 1:50 (Figure 1a). The mixture was subsequently homogenized by stirring for $12 \mathrm{~h}$ and lyophilized at $-60{ }^{\circ} \mathrm{C}$ for $48 \mathrm{~h}$. The resultant lyophilized system was heated at $60{ }^{\circ} \mathrm{C}$ for 30 min to obtain a solvent-free porous liquid (PoLi-bCA) composite which could flow under gravity at this temperature (right bottom inset, Figure $1 \mathrm{a}$ ) and comprised $\approx 3 \% \mathrm{v} / \mathrm{v}$ and $\approx 16$ 
$\% \mathrm{v} / \mathrm{v}$ permanent voids/pore volume (from the silica nanorods) and bCA, respectively. It should be noted that the fluid-like property of the porous liquid composite could be attributed to the liquid-nature of polymer surfactant at room temperature. The transmission electron micrographs of PoLi provided an average outer dimensions of rods $\approx 185 \times 30 \mathrm{~nm}$, with a hollow core of dimension $\approx 70 \times 10 \mathrm{~nm}$ (pore size $\approx 15 \mathrm{~nm}$ across; TEM averaging of 50 nanorods), and indicated an amorphous shell structure (HRTEM, left inset) along with a retained hollow core of the nanorods in the composite liquid, PoLi-bCA, obtained after mixing with $\mathrm{bCA}$ (hydrodynamic diameter $\approx 5.3 \mathrm{~nm}$ using DLS; SI Figure $\mathrm{S} 4 \mathrm{~b}$ ). The microstructure studies of the samples performed using small angle X-ray scattering (SI, Figure S3) indicated correlation peaks at $q\left(\AA^{-1}\right) \approx 0.051(\mathrm{PoLi}), 0.035(\mathrm{bCA})$, and 0.030 (PoLi-bCA) corresponding to a $d$-spacing (calculated using $d=2 \pi / q$ ) of $12.3,17.9$, and 20.9 $\mathrm{nm}$, respectively. This suggested that the average centre-to-centre distance between the silica rods increased on the inclusion of bCA during the synthesis of composite liquid. Another correlation peak at $q \approx 0.134 \AA^{-1}$, corresponding to $d \approx 4.7 \mathrm{~nm}$, was evident for all the samples, and was attributed to the centre-to-centre spacing between the polymer-surfactant shell on the hollow silica rods or the carbonic anhydrase enzyme. The thermal transitions associated with the composite sample were understood using differential scanning calorimetry (DSC). The DSC curves from $-70{ }^{\circ} \mathrm{C}$ to $+70^{\circ} \mathrm{C}$ (Figure $1 \mathrm{~b}$ ) for the solvent-free samples PoLi, bCA, and PoLi-bCA showed exothermic second-order glass transition temperatures, $T_{g}$, at $-48{ }^{\circ} \mathrm{C},-54{ }^{\circ} \mathrm{C}$, and $-56{ }^{\circ} \mathrm{C}$, respectively. Upon further heating, exothermic peaks at $-6{ }^{\circ} \mathrm{C},-16{ }^{\circ} \mathrm{C},-22{ }^{\circ} \mathrm{C}$, and endothermic peaks at $6{ }^{\circ} \mathrm{C}, 23{ }^{\circ} \mathrm{C}, 20{ }^{\circ} \mathrm{C}$ corresponding to the crystallisation, $T_{c}$, and melting, $T_{m}$, temperatures respectively, were observed for PoLi, bCA and PoLi-bCA samples. This suggested that all the samples behaved liquid-like at room temperature. In fact the temperature-sweep $\left(25\right.$ to $\left.50{ }^{\circ} \mathrm{C}\right)$ rheology experiment performed at a constant shear rate of $1 \mathrm{~s}^{-1}$ (Figure 1c) showed that the viscosity of 
the solvent-free composite liquid, PoLi-bCA was $\approx 9.7 \mathrm{~Pa} . \mathrm{s}$ at $25{ }^{\circ} \mathrm{C}$ which reduced approximately to $\approx 2 \mathrm{~Pa} . \mathrm{s}$ at $50^{\circ} \mathrm{C}$, and was intermediate of the viscosities observed for PoLi (4.8 Pa.s) and bCA (21.5 Pa.s), respectively at $25^{\circ} \mathrm{C} . \mathrm{CO}_{2}$ gas adsorption measurements performed on the PoLi at $0{ }^{\circ} \mathrm{C}$ showed an uptake of $\approx 5.5 \mathrm{ccg}^{-1}$, which were lesser by a factor of $\approx 4$ when compared to $\mathrm{CO}_{2}$ uptake by the precursors for PoLi i.e., bare hollow silica nanorods (SNR; $\left.22 \mathrm{ccg}^{-1}\right)$ or organosilane modified hollow silica nanorods (OS@SNR; 17 $\mathrm{ccg}^{-1}$ ) (SI, Figure S2b). However, this confirmed the presence of accessible permanent pores PoLi and was in accordance with previously shown studies. ${ }^{23}$ The PoLi-bCA sample showed similar $\mathrm{CO}_{2}$ uptake capacity $\left(\approx 5 \mathrm{ccg}^{-1}\right)$ at $0.03 \mathrm{P} / \mathrm{P}_{o}$, suggesting that inclusion of bCA did not lead to blockage of tortuous pores in the amorphous silica walls rods and that the hollow core was still accessible for $\mathrm{CO}_{2}$ adsorption (Figure $1 \mathrm{~d}$ ); bCA showed adsorption $\left(\approx 1 \mathrm{ccg}^{-1}\right.$ ) by itself. Furthermore, circular dichroism based secondary structural analysis of the enzyme in PoLi-bCA showed a random coil confirmation exhibited by a negative peak at $198 \mathrm{~nm}$ (SI, Figure S5). This was similar to the structure of carbonic anhydrase in the pure bCA sample (SI, Figure S4) where it showed a prominent random coil signature with peak minima at 198 $\mathrm{nm}$, thus suggesting retention of secondary structure of carbonic anhydrase after mixing with PoLi.

The next logical step was to understand whether the PoLi-bCA composite liquid could be used to sequester $\mathrm{CO}_{2}$ gas from any high pressure discharging platforms, and further ascertain its catalytic ability to convert $\mathrm{CO}_{2}$ into other compounds. It was envisaged, whilst the silica nanorods would sequester $\mathrm{CO}_{2}$ in the previously depressurised hollow cores, the carbonic anhydrase enzyme, would hydrate $\mathrm{CO}_{2}$ to form bicarbonate ions. However for the detection of bicarbonate ions, auxiliary component in the form of $\mathrm{Ca}^{2+}\left(\approx 450 \mathrm{nM} \mathrm{CaCl}_{2}\right)$ was introduced in the system (now labelled as PoLi-bCA/CaCl 2 ), such that the hydrated $\mathrm{CO}_{2}$ results in the formation of calcium carbonate, $\mathrm{CaCO}_{3}$. The sequestration of $\mathrm{CO}_{2}$ in the hollow 
silica nanorods within PoLi-bCA sample was done using an in-house built set-up (SI, Figure S6) for a period of $3 \mathrm{~h}$ at room temperature $\left(P_{\mathrm{in}}=3 \mathrm{~atm}\right)$. It was visually observed that bulk sample, over a period of time showed an increase in opacity within the sample (Figure S6), which prompted us to perform UV-vis transmittance studies. Figure 2a represents the transmittance spectra using monochromatic $\lambda_{\max }=630 \mathrm{~nm}$ light recorded every $1 \mathrm{~h}$ (during the purging of $\mathrm{CO}_{2} @ P_{\text {in }}$ for a total of $3 \mathrm{~h}$ ), and thereafter every $12 \mathrm{~h}$ (till 120 h), for PoLibCA/ $/ \mathrm{CaCl}_{2}$ and all other control samples viz. bCA $/ \mathrm{CaCl}_{2}, \mathrm{PoLi} / \mathrm{CaCl}_{2}$ and $\mathrm{PS} / \mathrm{CaCl}_{2}$. During the first $3 \mathrm{~h}$ of purging $\mathrm{CO}_{2}$ in PoLi-bCA/CaCl 2 the transmittance decreased by $\approx 20 \%$, whilst a relatively slower but $\approx 69.5 \%$ decrease was observed thereafter (i.e. after removal of $\mathrm{CO}_{2}$ pressurisation), till $120 \mathrm{~h}$. Meanwhile, in the case of $\mathrm{bCA} / \mathrm{CaCl}_{2}$, the percentage transmittance decreased at a faster rate of $\approx 57 \%$ in the first $3 \mathrm{~h}$, and thereafter $\approx 43 \%$ change was observed in the next $20 \mathrm{~h}$; there was negligible change in percentage transmittance afterwards. A plausible explanation at this point to the decrease in \%transmission could be associated to the formation of carbonate complexes with $\mathrm{Ca}^{2+}$ dispersed in the system. Closer inspection of the data provided at least two distinct quasi-linear regions, before and after $3 \mathrm{~h}$, associated with the transmission changes. This could be attributed to the stoppage in $\mathrm{CO}_{2}$ purging thus affecting the rate of formation of $\mathrm{CaCO}_{3}$ complexes. It was interesting to note that the control samples viz. $\mathrm{PoLi} / \mathrm{CaCl}_{2}$ and $\mathrm{PS} / \mathrm{CaCl}_{2}$ did not show any remarkable change in the transmittance with time, which could be attributed to the absence of carbonic anhydrase. Overall the transmission studies suggested that during the first three hours, $\mathrm{CO}_{2}$ was sequestered in the hollow silica nanorods comprising PoLi-bCA/CaCl 2 , whereafter it was slowly released over $\approx 120 \mathrm{~h}$ (as compared to only $\approx 20 \mathrm{~h}$ for $\mathrm{bCA} / \mathrm{CaCl}_{2}$ ) for it to be converted to larger complexes which scattered light. Control experiment involving no $\mathrm{CO}_{2}$ purging in PoLi-bCA/CaCl 2 (SI, Figure S7) showed no change in transmission values, thus, asserting further that percentage transmittance decrease was only due to the conversion of 
$\mathrm{CO}_{2}$ to $\mathrm{CaCO}_{3}$ due to bCA, a process that could be slowed down by having $\mathrm{CO}_{2}$ trapped in PoLi. To investigate the microstructure responsible for decrease in transmittance, timedependent polarized optical microscopy (POM) studies were performed at $30{ }^{\circ} \mathrm{C}$ on a droplet of PoLi-bCA $/ \mathrm{CaCl}_{2} / \mathrm{CO}_{2}$ taken on a glass slide and sandwiched with a cover slip (Figure $2 \mathrm{~b}$ g, SI Figure S8 and S9; Movie S1). Figure 2(b, c) represent the bright-field parallel and cross POM images of PoLi-bCA/CaCl 2 , respectively. After sequestration of $\mathrm{CO}_{2}$ for $3 \mathrm{~h}$ in PoLi$\mathrm{bCA} / \mathrm{CaCl}_{2}$ the POM images were captured at an interval of $12 \mathrm{~h}$ (Figure $2 \mathrm{~d}$, e) and $24 \mathrm{~h}$ (Figure 2f, g). The micrographs clearly showed the emergence of particles with various shapes like pseudo-cubical, and rod-like, which grew significantly in dimensions from $\approx 14.7$ $\times 9.9 \mu \mathrm{m}$ at $12 \mathrm{~h}$ to $\approx 18.5 \mu \mathrm{m} \times 13.25 \mu \mathrm{m}$ over $48 \mathrm{~h}$ (SI, Figure S8i). Interestingly, the morphology of these particles resembled with the $\mathrm{CaCO}_{3}$ crystals as reported in the literature, ${ }^{33,34}$ thus suggesting the conversion of $\mathrm{CO}_{2}$ to $\mathrm{HCO}_{3}^{-}$ion which subsequently reacted with $\mathrm{Ca}^{2+}$ ions to form $\mathrm{CaCO}_{3}$ crystals. The decrease in transmittance of PoLi$\mathrm{bCA} / \mathrm{CaCl}_{2} / \mathrm{CO}_{2}$ over a period of time as shown in Figure $2 \mathrm{a}$ could therefore be attributed to the formation of these $\mathrm{CaCO}_{3}$ crystals. While similar POM studies (after sequestration of $\mathrm{CO}_{2}$ ) for control $\mathrm{PoLi} / \mathrm{CaCl}_{2}$ (i.e. without bCA; SI, Figure $\mathrm{S} 10$ ) or $\mathrm{PS} / \mathrm{CaCl}_{2}$, did not show any evidence of particles (correlating well with the transmittance data), the POM for $\mathrm{bCA} / \mathrm{CaCl}_{2}$ (SI, Figure S11 and S12) indicated the formation of pseudo-cubical shaped but rather much irregular crystals, concluding that bCA was primarily responsible for $\mathrm{CaCO}_{3}$ formation. Time dependent POM studies performed on PoLi-bCA/ $\mathrm{CaCl}_{2}$ samples but without passing $\mathrm{CO}_{2}$ (SI, Figure S13) showed no indication of rhombohedral or rod-like $\mathrm{CaCO}_{3}$ particles, however, a network of needle-like structures formed in $48 \mathrm{~h}$ (SI, Figure S13), plausibly as a result of $\mathrm{CaCl}_{2}$ crystallization. Thus it could be concluded, whilst the PoLi successfully sequestered $\mathrm{CO}_{2}$, bCA catalyzed the conversion of slow releasing $\mathrm{CO}_{2}$ into $\mathrm{CaCO}_{3}$ by the mechanism as shown in schematic, Figure $\mathbf{2 h}$. The active site of bovine 
carbonic anhydrase comprising $\mathrm{Zn}^{2+}$ central metal ion is surrounded by four co-ordinating ligands: three histidine residues (His 93, His 95 and $\mathrm{His} 118$ ) and one $\mathrm{H}_{2} \mathrm{O}$ molecule. The first step in the catalytic reaction involved deprotonation of $\mathrm{Zn}^{2+}$ bound $\mathrm{H}_{2} \mathrm{O}$ to form nucleophilic $\mathrm{OH}^{-}$, which attacks the incoming $\mathrm{CO}_{2}$ in the second step which is followed by the formation of $\mathrm{Zn}^{2+}-\mathrm{HCO}_{3}{ }^{-}$complex in the third step. Finally, the regeneration of the enzyme/active site occurs with the simultaneous release of $\mathrm{HCO}_{3}{ }^{-}$ion as a result of addition of water molecule from the residual reservoir. ${ }^{35,36}$ The $\mathrm{HCO}_{3}{ }^{-}$ions finally reacted with the dispersed $\mathrm{CaCl}_{2}\left(\mathrm{Ca}^{2+}\right)$ resulting in the formation of $\mathrm{CaCO}_{3}$ crystals, plausibly having pseudo-cubic structure. ${ }^{37,38}$ In order to conclusively comment on the morphology and crystalline structure of $\mathrm{CaCO}_{3}$ crystals we further analyzed the samples using electron microscopy and diffraction studies.

The resultant crystalline structures within PoLi-bCA/CaCl $\mathrm{C}_{2}$ sample before and after passing $\mathrm{CO}_{2}$ were examined using SEM, TEM, SAED and XRD characterization tools. Figure 3a represents the characteristic SEM image of $\mathrm{PoLi}-\mathrm{bCA} / \mathrm{CaCl}_{2} / \mathrm{CO}_{2}$ (i.e. after passing $\mathrm{CO}_{2}$ ), whereby crystals having average dimensions of $\approx 115 \times 103 \mathrm{~nm}$ and plausibly resembling rhombohedral calcite crystals could be observed. ${ }^{38-43}$ A significant polydispersity in size was observed with the largest crystal dimensions being ca. $350 \times 305 \mathrm{~nm}$ (Figure 3a, inset). Also, at certain areas within the sample, rod-like (length $\approx 1.7 \mu \mathrm{m}$, width $\approx 190 \mathrm{~nm}$ ) and sphere-like crystals (average diameter $\approx 150 \mathrm{~nm}$ ) (SI, Figure S14b, c), suggesting the probable formation of aragonite and vaterite, respectively. ${ }^{44-47}$ SEM image of control sample, PoLi-bCA/ $\mathrm{CaCl}_{2}$ with no $\mathrm{CO}_{2}$ purged, did not show any $\mathrm{CaCO}_{3}$ crystals, except the presence of silica nanorods (SI, Figure S14a). In order to investigate the role of bCA, SEM for control sample bCA/ $\mathrm{CaCl}_{2}$ after passing $\mathrm{CO}_{2}$ (SI; Figure S15) showed the formation of aggregates of pseudo-cubic and rod-like crystals. These results accorded well with our POM studies, and 
confirmed that polymorphs of $\mathrm{CaCO}_{3}$ formed only in the presence of $\mathrm{CO}_{2}$, and further substantiated the role of bCA as a catalyst for the conversion of $\mathrm{CO}_{2}$ to $\mathrm{CaCO}_{3}$.

TEM images of PoLi-bCA/ $\mathrm{CaCl}_{2} / \mathrm{CO}_{2}$ (Figure 3b; SI, Figure S16) also depicted the formation of different sizes of pseudo-cubical i.e., $\approx 40 \times 33 \mathrm{~nm}, 135 \times 125 \mathrm{~nm}$ and $775 \times$ $590 \mathrm{~nm}$, and rod-like crystals of dimensions $\approx 578 \times 72 \mathrm{~nm}$, suggesting the formation of rhombohedral calcite and rod-like aragonite phase, respectively, ${ }^{37,38,44,45}$ and accorded well with our SEM data. The polydispersity in size could be attributed to the presence of different nucleation sites providing crystal growth in an uncontrolled manner. The high resolution TEM image of the pseudo-cubical crystal formed in PoLi-bCA/CaCl $/ \mathrm{CO}_{2}$ provided a lattice spacing of $0.28 \mathrm{~nm}$ corresponding to (006) plane of rhombohedral calcite crystal. The formation of $\mathrm{CaCO}_{3}$ crystal was also investigated from SAED pattern (Figure 3c). The existence of bright spots indicated the crystalline nature of PoLi-bCA/CaCl $2 / \mathrm{CO}_{2}$. SAED pattern of the sample provided lattice spacing of $0.162 \mathrm{~nm}$ and $0.152 \mathrm{~nm}$, corresponding to (211) and (214) planes of calcite crystal, respectively. Significantly, such crystal structures were not evident in the TEM micrograph of composite porous liquid not purged with $\mathrm{CO}_{2}$ (i.e. PoLi-bCA/CaCl 2 ; SI, Figure S16a), only showed the presence of hollow silica nanorods. The XRD pattern (Figure 3d; SI, Figure S17) of PoLi-bCA, PoLi-bCA/CaCl 2 , PoLibCA $/ \mathrm{CaCl}_{2} / \mathrm{CO}_{2}$ were also recorded to identify different crystal structures. PoLi-bCA showed amorphous structure due to the presence of polymer and silica (correlating well with the scattering halo seen in SAED up till $4 \mathrm{~nm}^{-1}$ ), whereas, after addition of $\mathrm{CaCl}_{2}$ i.e., PoLi$\mathrm{bCA} / \mathrm{CaCl}_{2}$, the XRD pattern showed crystalline peaks at $2 \theta=28.42^{\circ}, 40.67^{\circ}, 50.34^{\circ}, 58.79^{\circ}$, $66.43^{\circ}$ and $73.81^{\circ}$, that were attributed to (200), (220), (311), (400), (331) and (042) lattice planes of $\mathrm{CaCl}_{2}$, respectively (JCPDS\#74-0522). ${ }^{48}$ The $2 \theta$ values corresponding to $\mathrm{CaCl}_{2}$ lattice planes were summarized in Table S1, SI. Control XRD of $\mathrm{PS} / \mathrm{CaCl}_{2}$ sample (SI, Figure S17) showed similar peaks to that of PoLi-bCA/CaCl 2 thereby confirming the 
existence of $\mathrm{CaCl}_{2}$ lattice planes. However, after the sequestration of $\mathrm{CO}_{2}$, i.e. PoLi$\mathrm{bCA} / \mathrm{CaCl}_{2} / \mathrm{CO}_{2}$ sample showed several sets of prominent peaks. One set of peaks at $2 \theta=$ $23.33^{\circ}, 29.29^{\circ}, 31.23^{\circ}, 35.93^{\circ}, 39.66^{\circ}, 42.99^{\circ}, 47.82^{\circ}, 48.40^{\circ}, 48.94^{\circ}, 56.72^{\circ}$ and $60.70^{\circ}$ corresponded to (012), (104), (006), (110), (113), (202), (024), (018), (116), (211) and (214) planes of $\mathrm{CaCO}_{3}$ calcite crystal, respectively (PDF\#05-0586). ${ }^{43}$ Meanwhile, the other set of peaks observed at $2 \theta$ values $26.33^{\circ}, 33.47^{\circ}, 37.04^{\circ}, 41.47^{\circ}, 45.22^{\circ}, 50.69^{\circ}, 52.99^{\circ}, 53.47^{\circ}$, $59.47^{\circ}, 60.25^{\circ}$ and $63.78^{\circ}$ matched well with the (111), (012), (031), (131), (221), (132), (231), (023), (311), (051) and (151) lattice planes of aragonite crystal, respectively (PDF\#411475; SI, Figure S17). ${ }^{49}$ The existence of vaterite crystals were also identified with respect to the peak positions observed at $2 \theta=20.89^{\circ}, 32.89^{\circ}, 38.95^{\circ}, 40.89^{\circ}, 42.02^{\circ}, 50.20^{\circ}, 51.28^{\circ}$ and $68.39^{\circ}$ indicating the presence of (004), (114), (211), (116), (213), (118), (220) and (228) lattice planes, respectively (PDF\#33-0268; SI, Figure S17). ${ }^{49}$ All the lattice planes corresponding to $\mathrm{CaCO}_{3}$ crystal structure were summarized in Table S2, SI. Time dependent XRD data comparisons (SI, Figure S18) of PoLi-bCA/ $\mathrm{CaCl}_{2}$ composite liquid, before and after being purged with $\mathrm{CO}_{2}$ for $3 \mathrm{~h}$, indicated gradual appearances of all the abovementioned peaks (indexed to different polymorphs of $\mathrm{CaCO}_{3}$ ) at different $2 \theta$ values, which further grew in intensity over $24 \mathrm{~h}$. Thus, it indicated that although $\mathrm{CaCO}_{3}$ nucleation was fast, however, a slow growth occurred over 24 to $48 \mathrm{~h}$, which was consistent with the POM and turbidity data. This provided thorough and direct evidence that the composite porous liquid, $\mathrm{PoLi}-\mathrm{bCA} / \mathrm{CaCl}_{2}$, acted as a potential catalyst for the conversion of $\mathrm{CO}_{2}$ to $\mathrm{CaCO}_{3}$.

Further, we could recycle PoLi-bCA catalytic liquid by dissolving it back in water, centrifuging down micron-sized $\mathrm{CaCO}_{3}$ at $500 \mathrm{rpm}$, taking the supernatant (comprising dispersed nanoconjugates) and lyophilizing after adding requisite amount of $\mathrm{CaCl}_{2}$. The recyclability experiments were performed by sequestering $\mathrm{CO}_{2}$ in the recycled PoLi$\mathrm{bCA} / \mathrm{CaCl}_{2}$ for 10 minutes followed by time-dependent monitoring the formation of $\mathrm{CaCO}_{3}$ 
using POM (SI, Figure S19). In the first re-cycle, micron-sized $\mathrm{CaCO}_{3}$ crystals formed within $12 \mathrm{~h}$, whereas for $2^{\text {nd }}, 3^{\text {rd }}$ and $4^{\text {th }}$ re-cycles, it took $24 \mathrm{~h}, 48 \mathrm{~h}$ and $60 \mathrm{~h}$ respectively. These studies depicted the high efficiency of the catalyst PoLi-bCA/CaCl 2 which can be used effectively over 4 cycles. Moreover, $\mathrm{CO}_{2}$ storage in $\mathrm{PoLi}-\mathrm{bCA} / \mathrm{CaCl}_{2}$ porous liquid composite could also be activated by reducing the temperature of the system, below its $T_{g}$ of $-50{ }^{\circ} \mathrm{C}$, after sequestration with $\mathrm{CO}_{2}$. At these temperatures the formation of $\mathrm{CaCO}_{3}$ was totally quenched (SI, Figure S20). This occurred as a result of trapping/permanent storage of $\mathrm{CO}_{2}$ (monitored over $48 \mathrm{~h}$ ) within the hollow cores of silica nanorods which were now covered with a glassy, immobile and impenetrable layer of PS, below the $T_{g}$. Increasing the temperature back to room temperature melted the PS chains, thus reinitiating the release of $\mathrm{CO}_{2}$ from the hollow cores, and the subsequent bCA mediated catalytic conversion to $\mathrm{CaCO}_{3}$. The conversion of $\mathrm{CO}_{2}$ to $\mathrm{HCO}_{3}{ }^{-}$is accompanied by a change in $\mathrm{pH}$ of the system. In comparison to porous solids it is expected that $\mathrm{PoLi}-\mathrm{bCA} / \mathrm{CaCl}_{2}$ porous liquid composite would show faster mass transfer/diffusion of the molecules between bulk and surface, dispersed within the system. Therefore, one can envisage to visualize the process of $\mathrm{pH}$ change by incorporating a $\mathrm{pH}$ sensitive amino-dye, Neutral Red (NR), in PoLi-bCA/CaCl 2 system. The $\mathrm{pH}$ of $\mathrm{PoLi}-\mathrm{bCA} / \mathrm{CaCl}_{2} / \mathrm{NR}$ sequestered with $\mathrm{CO}_{2}$ had a $\mathrm{pH} \approx 5.5$, and therefore NR exhibited a red colour as seen in POM image shown in Figure 4a. Over a period of $48 \mathrm{~h}$, as the $\mathrm{CO}_{2}$ catalytically converted to $\mathrm{HCO}_{3}{ }^{-}$and further slowly into $\mathrm{CaCO}_{3}$ crystals (Figure 4b and inset), the $\mathrm{pH}$ of the sample changes to 7, with simultaneous change in colour of NR to yellow from red. Colour transition of PoLi-bCA $/ \mathrm{CaCl}_{2} / \mathrm{NR}$ bulk samples in a glass cuvette was also monitored using UV-visible spectroscopy at $30{ }^{\circ} \mathrm{C}$ before, and at regular time intervals after sequestering $\mathrm{CO}_{2}$ (Figure 4c). Strong absorbance peak at $\lambda_{\max }=544 \mathrm{~nm}$ (protonated NR) along with a low intensity peak at $460 \mathrm{~nm}$ (unprotonated NR) was seen before and after $0 \mathrm{~h}$ of passing $\mathrm{CO}_{2}{ }^{50}$ However, a blue shift from $544 \mathrm{~nm}$ to $532 \mathrm{~nm}$ was 
observed within $24 \mathrm{~h}$, which could be attributed to the decrease in protonation of NR as the $\mathrm{pH}$ approached $6{ }^{[50]}$ After $48 \mathrm{~h}$ as the micron-sized $\mathrm{CaCO}_{3}$ crystals appeared, and resulted in increased background scattering, the peak at $532 \mathrm{~nm}$ nearly disappeared, whereas $460 \mathrm{~nm}$ peak exhibited blue shift of $10 \mathrm{~nm}$. The peak at $450 \mathrm{~nm}$ emerges due to the existence of neutral form of $\mathrm{NR}$ dye ${ }^{50}$ which confirmed an increase in $\mathrm{pH}$ to 7 in the PoLi$\mathrm{bCA} / \mathrm{CaCl}_{2} / \mathrm{NR} / \mathrm{CO}_{2}$ due to the formation of $\mathrm{CaCO}_{3}$, and concurrent with the change in colour of NR from red to yellow. This experiment, therefore, served as a potential proof of concept in terms of a visualization methodology for the conversion of $\mathrm{CO}_{2}$ into a useful material.

In order to validate and harness the advantage of liquid-like nature of our composite material, we sought to investigate whether similar $\mathrm{CaCO}_{3}$ formation and the associated $\mathrm{pH}$ changes could be achieved by the diffusion of complimentary ions (viz. the generated $\mathrm{HCO}_{3}{ }^{-}$ and auxiliary $\mathrm{Ca}^{2+}$ ) separated by a permeable boundary? Therefore, an experiment was designed by creating an interface between two liquid droplets: one comprising $\mathrm{PS} / \mathrm{CaCl}_{2} / \mathrm{NR}$ and the other one PoLi-bCA/CO 2 . A PDMS mould (Figure 4d) with two circular compartments (diameter of each $\approx 4.3 \mathrm{~mm}$ ) connected by a narrow rectangular slit (length $\approx$ $3.3 \mathrm{~mm}$, width $\approx 1.0 \mathrm{~mm}$ ) was fabricated. The left compartment was filled with PoLi$\mathrm{bCA} / \mathrm{CO}_{2}$, while the red coloured $\mathrm{PS} / \mathrm{CaCl}_{2} / \mathrm{NR}$ was filled in the right compartment, with both materials meeting in between the slit. The mould was sealed with glass cover slip and the time dependent changes in both the compartments as well as the interface were monitored using POM at $30{ }^{\circ} \mathrm{C}$ (Figure 4f-i; SI, Figure S21). It is expected that the diffusivity of $\mathrm{Ca}^{2+}$ (right-side compartment) and $\mathrm{HCO}_{3}{ }^{-}$(formed in the left compartment) will be much higher than that of NR (right compartment) and therefore, an appreciable $\mathrm{pH}$ induced colour change from red to yellow/ or formation of $\mathrm{CaCO}_{3}$ would be seen at interface. Significant changes in the parallel POM showing the colour and texture at the interface were only observed after 48 
h (compare Figure 4f, h), whereas cross-polarized micrographs (Figure 4i, and inset) showed the formation of $\mathrm{CaCO}_{3}$ calcite crystals. POM of the right-side compartment (PS/CaCl $2 / \mathrm{NR}$; SI, Figure S21c-f) even after $48 \mathrm{~h}$ showed no significant changes from the $0 \mathrm{~h}$ data (pink colour and no crystals), which asserted that the diffusivity of $\mathrm{HCO}_{3}{ }^{-}$ions was slow and not completed within 48 h. Significantly, POM of left-side compartment (PoLibCA/ $\mathrm{CO}_{2}$ ), indicated the formation of $\mathrm{CaCO}_{3}$ crystals after $48 \mathrm{~h}$ (SI, Figure S21k-n), suggesting that $\mathrm{Ca}^{2+}$ ions diffused faster from the right to left compartment through the narrow slit interface and reacted with $\mathrm{HCO}_{3}{ }^{-}$ions to form $\mathrm{CaCO}_{3}$ crystals, however, the number density of crystals was much lower than at the interface. The higher diffusion $(D)$ of $\mathrm{Ca}^{2+}(a=100 \mathrm{pm})$ compared to that of $\mathrm{HCO}_{3}^{-}(a=156 \mathrm{pm})$ ions by a factor of $\approx 2.3$ times (calculated using Stokes-Einstein relation $D=k T / 6 \pi \eta a$ ) was attributed to the lower viscosity of right side compartment $\left(\eta_{25}{ }^{\circ} \mathrm{C}\right.$ for $\mathrm{PS} / \mathrm{CaCl}_{2} / \mathrm{NR} \approx 7.1$ Pa.s $)$ compared to left side compartment $\left(\eta_{25}{ }^{\mathrm{C}} \mathrm{C}\right.$ for PoLi-bCA/CO $2 \approx 10.3$ Pa.s) (SI, Figure S22).

To summarize, we report a novel and facile method for the fabrication of solvent-less and porous liquid composite, PoLi-bCA, by mixing polymer surfactant conjugated hollow silica nanorods and bioconjugated carbonic anhydrase enzyme. Whilst the hollow silica nanorods provide an intrinsic, permanent, and accessible mesoporosity for $\mathrm{CO}_{2}$ sequestration (at $0{ }^{\circ} \mathrm{C} / 0.03 P / P_{o}$ and $30{ }^{\circ} \mathrm{C} / 0.03 P / P_{o}$ ) and storage (at $-60{ }^{\circ} \mathrm{C}$ i.e. below the $T_{g}$ ), bCA acted as a catalyst for the conversion of slowly releasing $\mathrm{CO}_{2}$ to $\mathrm{HCO}_{3}{ }^{-}$ions, which were detected in the form of $\mathrm{CaCO}_{3}$ by the addition of auxiliary $\mathrm{CaCl}_{2}$. The formation of $\mathrm{CaCO}_{3}$ resulted in decreased transmittance of the composite liquid by $\approx 75 \%$ over $120 \mathrm{~h}$, however, in absence of hollow silica nanorods the percentage transmittance decreased $\approx 75 \%$ in only $24 \mathrm{~h}$ i.e., at a much faster rate, suggesting that the hollow rods trapped the $\mathrm{CO}_{2}$ and released it slowly into its environment. Light and electron microscopy confirmed the formation of rhombohedral calcite and rod-like aragonite $\mathrm{CaCO}_{3}$ crystals, whereas XRD pattern also indicated the 
formation of vaterite, other polymorph of $\mathrm{CaCO}_{3}$. This material was shown to be recyclable upto 4 times with considerable activity of bCA retained. Furthermore, since the $\mathrm{CO}_{2}$ to $\mathrm{CaCO}_{3}$ conversion is associated with a $\mathrm{pH}$ change from $\approx 5$ to $\approx 7$, it could be visually identified by the red to yellow color transition of the auxiliary $\mathrm{pH}$ indicator dye. We also harnessed the liquid-like nature of the composite by demonstrating the diffusion of complimentary ions responsible for $\mathrm{CaCO}_{3}$ formation through two different compartments kept in contact using a narrow channel. We believe to the best of our knowledge, this is the first example of facile fabrication of such a solvent-less composite porous liquid which not only acts as a adsorption and storage medium for $\mathrm{CO}_{2}$, but also act as a reaction media in which adsorbed gases can be catalytically converted to non-hazardous and utility chemicals, and thereby offers a new route towards sustainable development.

\section{Experimental}

Synthesis of solvent-less liquid composite (PoLi-bCA) comprising polymer-surfactant coated hollow/porous silica nanorods (porous liquid; PoLi) and bioconjugated carbonic anhydrase $(b C A)$ :

The solvent-less liquid composite PoLi-bCA was prepared by mixing $700 \mathrm{mg}$ of PoLi and $336 \mathrm{mg}$ of bCA (number ratio of PoLi and $\mathrm{bCA} \approx 1: 50)$ in phosphate buffer $(10 \mathrm{mM}, \mathrm{pH}=$ 5.8) and stirred for $12 \mathrm{~h}$. Thereafter, the solution was lyophilized to remove water and heated at $60^{\circ} \mathrm{C}$ to achieve PoLi-bCA composite liquid, which was sealed and used for further experiments.

Characterization of sequestration, storage and catalytic conversion of $\mathrm{CO}_{2}$ to $\mathrm{CaCO}_{3}$ in solvent-less composite liquid, PoLi-bCA:

The sequestration of $\mathrm{CO}_{2}$ in PoLi-bCA composite was carried out using an in-house built setup. Subsequent storage of $\mathrm{CO}_{2}$ could be achieved by reducing the temperature below the $T_{g}$ 
of the system, while the catalytic conversion to bicarbonate ions studies and its detection in the form of $\mathrm{CaCO}_{3}$ was performed by adding auxiliary $\mathrm{Ca}^{2+}$ ions. ${ }^{27} \mathrm{~A}$ sample comprising 1000 mg of PoLi-bCA and $0.1 \mathrm{mg} \mathrm{CaCl}{ }_{2} \cdot 6 \mathrm{H}_{2} \mathrm{O}(456 \mathrm{nM})$ was dispersed in $2 \mathrm{~mL}$ phosphate buffer (10 $\mathrm{mM}, \mathrm{pH}=5.8)$ and stirred for $3 \mathrm{~h}$. The mixture was then lyophilized for $48 \mathrm{~h}$, followed by heating at $60{ }^{\circ} \mathrm{C}$ to obtain solvent-less composite liquid, PoLi-bCA/CaCl 2 , which was finally taken for $\mathrm{CO}_{2}$ sequestration. In a typical sequestration experiment, $1000 \mathrm{mg}$ of PoLibCA/ $\mathrm{CaCl}_{2}$ was taken in a cuvette and de-evacuated at $60{ }^{\circ} \mathrm{C}$ for $10 \mathrm{~h}$. After that, the sample was sealed properly and $\mathrm{CO}_{2}$ was sequestered at 3 atm pressure into PoLi-bCA $/ \mathrm{CaCl}_{2}$ through a syringe needle for $3 \mathrm{~h}$ at room temperature (SI, Figure S6). Simultaneously, another needle was inserted into cuvette as an outlet to release the excess pressure. After the $\mathrm{CO}_{2}$ had been sequestered in the sample, the inlet and outlet needles were taken out, sample was tightly sealed and the percentage transmittance was measured using UV-visible spectroscopy $y^{27}$ at regular interval of time. The formation of $\mathrm{CaCO}_{3}$ decreased the transmittance of PoLi-bCA sample at $\lambda_{\max }=630 \mathrm{~nm} .{ }^{27}$ Three different solvent-less liquids for control studies viz. bCA/CaCl $2, \mathrm{PoLi} / \mathrm{CaCl}_{2}$ and $\mathrm{PS} / \mathrm{CaCl}_{2}$ were prepared similarly as discussed above, and used for $\mathrm{CO}_{2}$ sequestration, followed by transmission studies. Control experiments were also performed for PoLi-bCA/CaCl 2 (with no $\mathrm{CO}_{2}$ purged).

Time dependent POM studies were performed before and after passing $\mathrm{CO}_{2}$ for PoLi$\mathrm{bCA} / \mathrm{CaCl}_{2}, \mathrm{bCA} / \mathrm{CaCl}_{2}$ and $\mathrm{PoLi} / \mathrm{CaCl}_{2}$ over a period of time at $30{ }^{\circ} \mathrm{C}$ to investigate the formation of $\mathrm{CaCO}_{3}$ crystals. The POM studies were carried out by drop casting the solventless liquid samples on a glass slide kept in a temperature controlled Linkam stage. Moreover, for investigating the storage of $\mathrm{CO}_{2}$ in PoLi-bCA/CaCl 2 , temperature dependent POM studies were carried out immediately after passing $\mathrm{CO}_{2}$. The storage experiments were performed at $60{ }^{\circ} \mathrm{C}$ since the glass transition temperature of the composite liquid PoLi-bCA was found to be $-56{ }^{\circ} \mathrm{C}$ at which permeability of gases through the sample was ceased. Liquid nitrogen was 
connected to the Linkam stage for maintaining constant cooling rate.XRD, SEM and TEM were also recorded (before and after passing $\mathrm{CO}_{2}$ ) to investigate the formation of calcium carbonate crystals.

Visual observation of catalytic conversion of $\mathrm{CO}_{2}$ using a pH sensitive dye:

The after-effect of the sequestration of $\mathrm{CO}_{2}$ in the composite liquid sample comprising $\mathrm{Ca}^{2+}$ ions, i.e. PoLi-bCA/CaCl 2 , was in the form of slight increase in turbidity of the sample associated with the formation of $\mathrm{CaCO}_{3}$ that were observed using POM. However, for achieving a facile method of observation, a $\mathrm{pH}$ dependent dye, Neutral Red (NR), was introduced in the system. The $\mathrm{pH}$ of PoLi-bCA/CaCl 2 freshly sequestered with $\mathrm{CO}_{2}$ is $\approx 5.8$, however, with time as the formation of $\mathrm{CaCO}_{3}$ occurs, the $\mathrm{pH}$ tends to increase. Such a $\mathrm{pH}$ increase viz., the catalytic conversion of $\mathrm{CO}_{2}$, can be visualized by the colour transition of NR from red to yellow with change in $\mathrm{pH}$ from 6 to 8 . For this typical experiment, $0.01 \mathrm{mg}$ of NR dye $(0.001 \% \mathrm{w} / \mathrm{w}$ of PoLi-bCA/CaCl $2 ; 34.6 \mathrm{nM})$ was dispersed in $1000 \mathrm{mg}$ of PoLi$\mathrm{bCA} / \mathrm{CaCl}_{2}$ to form red coloured composite liquid termed as PoLi-bCA/CaCl$/ 2 \mathrm{NR}$. The sequestration of $\mathrm{CO}_{2}$ in PoLi-bCA/CaCl$/ 2 / \mathrm{NR}$ was carried in a sealed cuvette for $3 \mathrm{~h}$ in a similar manner as mentioned above. Apart from visual observations of red to yellow colour transition, $\mathrm{POM}$ experiments were also carried out by drop casting PoLi-bCA/ $\mathrm{CaCl}_{2} / \mathrm{NR} / \mathrm{CO}_{2}$ in a glass slide immediately after passing $\mathrm{CO}_{2}$ for $3 \mathrm{~h}$ and keeping in Linkam stage to maintain the temperature at $30{ }^{\circ} \mathrm{C}$. UV-vis studies (before and after sequestration of $\mathrm{CO}_{2}$ in PoLi-bCA/CaCl$/ 2$ NR) were also performed from $400-600 \mathrm{~nm}$ at regular intervals of time and $30{ }^{\circ} \mathrm{C}$, by sandwiching a thin layer of sample in between two quartz plates (path length $=0.01$ $\mathrm{mm})$.

Deploying reaction in Porous Liquid by Diffusion of Reactive Components:

In order to highlight the advantage of the liquid nature of the composite material the $\mathrm{CaCO}_{3}$ formation reaction was deployed by separating the complimentary reaction components in 
two different compartments interfaced using a channel. The diffusivity of ions viz. bicarbonate ions $\left(\mathrm{HCO}_{3}{ }^{-}\right)$formed by the hydration of $\mathrm{CO}_{2}\left(1^{\text {st }}\right.$ compartment $)$, and the $\mathrm{Ca}^{2+}$ ions $\left(2^{\text {nd }}\right.$ compartment) was observed across the two different compartments (size $\approx 4.3 \mathrm{~mm}$ ) separated by a narrow slit (length $\approx 3.3 \mathrm{~mm}$, width $\approx 1 \mathrm{~mm}$ ) made on a transparent PDMS mould. In the left compartment, PoLi-bCA/CO (after passing $\mathrm{CO}_{2}$ for $3 \mathrm{~h}$ ) was drop casted and the right compartment was filled with a drop of $\mathrm{PS} / \mathrm{CaCl}_{2} / \mathrm{NR}$ which was prepared by mixing $100 \mathrm{mg}$ PS, $0.01 \mathrm{mg} \mathrm{CaCl}_{2}(45.6 \mathrm{nM})$ and $0.001 \mathrm{mg} \mathrm{NR}(3.46 \mathrm{nM})$, and an interface was created between both the liquid droplets in the narrow channel. The PDMS mould was immediately sealed with a glass cover slip and the $\mathrm{pH}$ changes/formation of $\mathrm{CaCO}_{3}$ crystals at the interface, right and left compartments were monitored by POM at regular time intervals.

\section{Supporting Information}

Supporting Information (SI) is available seperately.

\section{Acknowledgements}

A.B. thanks Department of Chemistry, IITB for post-doctoral fellowship. The authors acknowledge Prof. Leela Srinivas Panchakarla, Department of Chemistry, IITB for useful discussions on XRD data. We thank Sushil Swaroop Pathak, Kuldeep Kumar, P.M. Naveenkumar and Anasua M. (Department of Chemistry, IITB) for helping in TEM, XRD, preparing PDMS mould, and protein visualization files, respectively.

\section{References}

1. Haszeldine, R.S.; Flude, S.; Johnson, G.; Scott, V. Negative emissions technologies and carbon capture and storage to achieve the Paris Agreement commitments. Phil. Trans. R. Soc. A. 2018, 376, 20160447.

2. Aresta, M.; Dibenedetto, A.; Angelini, A. The changing paradigm in $\mathrm{CO}_{2}$ utilization. $J$. $\mathrm{CO}_{2}$ Util. 2013, 3-4, 65-73.

3. Sevilla, M.; Fuertes, A.B. Sustainable porous carbons with a superior performance for $\mathrm{CO}_{2}$ capture. Energy Environ. Sci. 2011, 4, 1765-1771.

4. Lin, Y.; Kong, C.; Zhang, Q.; Chen L. Metal-Organic Frameworks for Carbon Dioxide Capture and Methane Storage. Adv. Energy Mater. 2017, 7, 1601296.

5. Hicks, J.C.; Drese, J.H.; Fauth, D.J.; Gray, M.L.; Qi, G.G.; Jones C.W. Designing Adsorbents for $\mathrm{CO}_{2}$ Capture from Flue Gas-Hyperbranched Aminosilicas Capable of Capturing $\mathrm{CO}_{2}$ Reversibly. J. Am. Chem. Soc. 2008, 130, 2902-2903. 
6. Wang, M.; Lawal, A.; Stephenson, P.; Sidders, J.; Ramshaw, C. Post-combustion $\mathrm{CO}_{2}$ capture with chemical absorption: A state-of-the-art review. Chem. Eng. Res. Des. 2011, 89, 1609-1624.

7. Bandyopadhyay, A. Amine versus ammonia absorption of $\mathrm{CO}_{2}$ as a measure of reducing GHG emission: a critical analysis, Clean Techn. Environ. Policy. 2011, 13, 269-294.

8. Lucquiaud, M.; Gibbins, J. On the integration of $\mathrm{CO}_{2}$ capture with coal-fired power plants: A methodology to assess and optimise solvent-based post-combustion capture systems. Chem. Eng. Res. Des. 2011, 89, 1553-1571.

9. O'Reilly, N.; Giri, N.; James, S.L. Porous Liquids. Chem. Eur. J. 2007, 13, 3020-3025.

10. Melaugh, G.;Giri, N.; Davidson, C.E.; James, S.L.; Pópolo, M.G.D. Designing and understanding permanent microporosity in liquids. Phys. Chem. Chem. Phys. 2014, 16, 9422-9431.

11. James, S.L. The damn bursts for porous liquid. Adv. Mater. 2016, 28, 5712-5716.

12. Mastalerz, M. Materials Chemistry: Liquified molecular holes. Nature. 2015, 527, 174176.

13. Cooper, A.I. Porous molecular solids and liquids. ACS Cent. Sci. 2017, 3, 544-553.

14. Greenaway, R.L.; Holden, D.; Eden, E.G.B.; Stephenson, A.; Yong, C.W.; Bennison, M.J.; Hasell, T.; Briggs, M.E.; James, S.L.; Cooper, A.I. Understanding gas capacity, guest selectivity and diffusion in porous liquids. Chem. Sci. 2017, 8, 2640-2651.

15. Giri, N.; Davidson, C.E.; Melaugh, G.; Pópolo, M.G.D.; Jones, J.T.A.; Hasell, T.; Cooper, A.I.; Horton, P.N.; Hursthouse, M.B.; James, S.L. Alkylated organic cages: from porous crystals to neat liquids. Chem. Sci. 2012, 3, 2153-2157.

16. Giri, N.; Pópolo, M.G.D.; Melaugh, G.; Greenaway, R.L.; Rätzke, K.; Koschine, T.; Pison, L.; Gomes, M.F.C.; Cooper, A.I.; James, S.L. Liquids with permanent porosity. Nature. 2015, 527, 216-221.

17. Shan, W.; Fulvio, P.F.; Kong, L.; Schott, J.A.; Do-Thanh, C.L.; Tian, T.; Hu, X.; Mahurin, S.M.; Xing, H.; Dai, S. New Class of Type III Porous Liquids: A Promising Platform for Rational Adjustment of Gas Sorption Behavior. ACS Appl. Mater. Interfaces. 2018, 10, 32-36.

18. Li, P.; Chen, H.; Schott, J.A.; Li, B.; Zheng, Y.; Mahurin, S.M.; Jiang, D.; Cui, G.; Hu, X.; Wang, Y.; Li, L.; Dai S. Porous liquid zeolites: hydrogen bonding-stabilized H-ZSM5 in branched ionic liquids. Nanoscale. 2019, 11, 1515-1519.

19. Zang, F.; Yang, F.; Huang, J.; Sumpter, B.G.; Qiao, R. Thermodynamics and kinetics of gas storage in porous liquids. J. Phys. Chem. B. 2016, 120, 7195-7200.

20. Gomes, M.C.; Pison, L.; Červinka, C; Padua, A. Porous ionic liquids or liquid metalorganic frameworks? Angew. Chem. Int. Ed. 2018, 57, 1-5.

21. Gaillac, R.; Pullumbi, P.; Beyer, K.A.; Chapman, K.W.; Keen, D.A.; Bennett, T.D.; Coudert, F.X. Liquid metal-organic frameworks. Nat. Mater. 2017, 16, 1149-1154.

22. Horike, S.; Kitagawa, S. Liquid porous materials: Unveiling liquid MOFs. Nat. Mater. 2017, 16, 1054-1055.

23. Kumar, R.; Dhasaiyan, P.; Naveenkumar, P.M.; Sharma K.P. A solvent-free porous liquid comprising hollow nanorod-polymer surfactant conjugates. Nanoscale Adv. 2019, $1,4067-4075$. 
24. Zhang, J.; Chai, S.H.; Qiao, Z.A.; Mahurin, S.M.; Chen, J.; Fang, Y.; Wan, S.; Nelson,K.; Zhhunang, P.; Dai, S. Porous Liquids: A Promising Class of Media for Gas Separation. Angew. Chem. Int. Ed. 2015, 54, $932-936$.

25. Shi, T.; Zheng, Y.; Wang, T.; Li, P.; Wang, Y.; Yao, D. Effect of pore size on the carbon dioxide adsorption behavior of porous liquids based on hollow silica. Chem. Phys. Chem. 2018, 19, 130-137.

26. Li, P.; Schott, J.A.; Zhang, J.; Mahurin, S.M.; Sheng, Y.; Qiao, Z.A.; Hu, X.; Cui, G.; Yao, D.; Brown, S.; Zheng, Y.; Dai, S. Electrostatic-assisted liquefaction of porous carbons. Angew. Chem. Int. Ed. 2017, 129, 15154-15158.

27. Jo, B.H.; Seo, J.H.; Yang, Y.J.; Baek, K.; Choi, Y.S.; Pack, S.P.; Oh, S.H.; Cha, H.J. Bioinspired Silica Nanocomposite with Autoencapsulated Carbonic Anhydrase as a Robust Biocatalyst for $\mathrm{CO}_{2}$ Sequestration. ACS Catal. 2014, 4, 4332-4340.

28. Vinoba, M.; Bhagiyalakshmi, M.; Jeong, S.K.; Yoon, Y.; Nam, S.C. Capture and Sequestration of $\mathrm{CO}_{2}$ by Human Carbonic Anhydrase Covalently Immobilized onto Amine-Functionalized SBA-15. J. Phys. Chem. C. 2011, 115, 20209-20216.

29. Perriman, A.W.; Mann, S. Liquid Proteins-A New Frontier for Biomolecule-Based Nanoscience. ACS Nano. 2011, 5, 6085-6091.

30. Brogan, A.P.S.; Sharma, K.P.; Perriman, A.W.; Mann, S. Enzyme activity in liquid lipase melts as a step towards solvent-free biology at $150{ }^{\circ} \mathrm{C}$. Nat. Commun. 2014, 5, 1-8.

31. Mukhopadhyay, A.; Das, T.; Datta, A.; Sharma, K.P. Neat Protein-Polymer Surfactant Bioconjugates as Universal Solvents. Biomacromolecules. 2018, 19, 943-950.

32. Gao, C., Lu, Z. \& Yin, Y. Gram-scale synthesis of silica nanotubes with controlled aspect ratios by templating of nickel-hydrazine complex nanorods. Langmuir. 2011, 27, 12201-12208.

33. Tomasini, C.; Castellucci, N.; Caputo, V.C.; Milli, L.; Battistelli, G.; Fermani, S.; Falini, G. Shaping calcite crystals by customized self-assembling pseudopeptide foldamers. Cryst. Eng. Comm. 2015, 17, 116-123.

34. Falini, G.; Manara, S.; Fermani, S.; Roveri, N.; Goisis, M.; Manganelli, G.; Cassar, L. Polymeric admixtures effects on calcium carbonate crystallization: relevance to cement industries and biomineralization. Cryst. Eng. Comm. 2007, 9, 1162-1170.

35. Fu, Y.; Jiang, Y. B.; Dunphy, D.; Xiong, H.; Coker, E.; Chou, S.; Zhang, H.; Vanegas, J.M.; Croissant, J.G.; Cecchi, J.L.; Rempe, S.B.; Brinker, C.J. Ultra-thin enzymatic liquid membrane for $\mathrm{CO}_{2}$ separation and capture. Nat. Commun. 2018, 9, 1-12.

36. Zhang, Y. T.; Zhang, L.; Chen, H.L.; Zhang, H.M. Selective separation of low concentration $\mathrm{CO}_{2}$ using hydrogel immobilized $\mathrm{CA}$ enzyme based hollow fiber membrane reactors. Chem. Eng. Sci. 2010, 65, 3199-3207.

37. Vinoba, M.; Bhagiyalakshmi, M.; Choi, S.Y.; Park, K.T.; Kim, H.J.; Jeong, S.K. Harvesting $\mathrm{CaCO}_{3}$ polymorphs from in-situ $\mathrm{CO}_{2}$ capture process. J. Phys. Chem. C. 2014, 118, 17556-17566.

38. Vinoba, M.; Bhagiyalakshmi, M.; Grace, A.N.; Chu, D.H.; Nam, S.C.; Yoon, Y.; Yoon, S.H.; Jeong, S.K. $\mathrm{CO}_{2}$ Absorption and Sequestration as Various Polymorphs of $\mathrm{CaCO}_{3}$ Using Sterically Hindered Amine. Langmuir. 2013, 29, 15655-15663. 
39. Kim, Y.Y.; Schenk, A.S.; Ihli, J.; Kulak, A.N.; Hetherington, N.B.J.; Tang, C.C.; Schmahl, W.W.; Griesshaber, E.; Hyett, G.; Meldrum, F.C. A critical analysis of calcium carbonate mesocrystals. Nat. Commun. 2014, 5, 1-14.

40. Ihli, J.; Clark, J. N.; Kanwal, N.; Kim, Y.Y.; Holden, M. A.; Harder, R. J.; Tang, C.C.; Ashbrook, S.E.; Robinson, I.K.; Meldrum, F.C. Visualization of the effect of additives on the nanostructures of individual bio-inspired calcite crystals. Chem. Sci. 2019, 10, $1176-1185$.

41. Marzec, B.; Green, D.C.; Holden, M.A.; Coté, A.S.; Ihli, J.; Khalid, S.; Kulak, A.; Walker, D.; Tang, C.; Duffy, D. M.; Kim, Y.Y.; Meldrum, F.C. Amino Acid Assisted Incorporation of Dye Molecules within Calcite Crystals. Angew. Chem. Int. Ed. 2018, 57, 8623-8628.

42. Shi, S.; Cai, L.; Liu, X.; Li, H.; Gao, Y.; Wu, Q.; Yi, J.; Song, X.; Zhang, G. Bioinspired fabrication of macroporous calcium carbonate crystals mediated by thermoresponsive copolymers. RSC Adv. 2017, 7, 44505-44513.

43. Liu, C.; Xie, L.; Zhang R. Heterogeneous distribution of dye-labelled biomineralization proteins in calcite crystals. Sci. Rep. 2015, 5, 1-8.

44. Zeng, M.; Kim, Y.; Anduix-Canto, C.; Frontera, C.; Laundy, D.; Kapur, N.; Christenson, H.K.; Meldrum, F.C. Confinement generates single-crystal aragonite rods at room temperature. PNAS. 2018, 115, 7670-7675.

45. Rodriguez-Navarro, C.; Elert, K.; Ševčík, R. Amorphous and crystalline calcium carbonate phases during carbonation of nanolimes: implications in heritage conservation. Cryst. Eng. Comm. 2016, 18, 6594-6607.

46. Meldrum, F.C.; Cölfen, H. Controlling Mineral Morphologies and Structures in Biological and Synthetic Systems. Chem. Rev. 2008, 108, 4332-4432.

47. Feoktistova, N.; Rose, J.; Prokopovic, V.Z.; Vikulina, A.S.; Skirtach, A.G.; Volodkin, D. Controlling the Vaterite $\mathrm{CaCO}_{3}$ Crystal Pores. Design of Tailor-Made Polymer Based Microcapsules by Hard Templating. Langmuir. 2016, 32, 4229-4238.

48. Zheng, H.; Ito, H.; Okabe, T.H. Production of titanium powder by the calciothermic reduction of titanium concentrates or ore using the preform reduction process. Mater. Trans. 2007, 48, 2244-2251.

49. Guo, H.; Sun, P.; Qin, Z.; Shan, L.; Zhang, G.; Cui, S.; Liang, Y. Sodium lignosulfonate induced vaterite calcium carbonate with multilayered structure. Eur. J. Inorg. Chem. 2014, 2014, 1001-1009.

50. Sousa, C.; Sa e Melo, T.; Geze, M.; Gaullier, J. M.; Maziere, J. C.; Santus, R. Solvent Polarity and pH Effects on the Spectroscopic Properties of Neutral Red: Application to Lysosomal Microenvironment Probing in Living Cells. Photochem. Photobiol. 1996, 63, 601-607. 


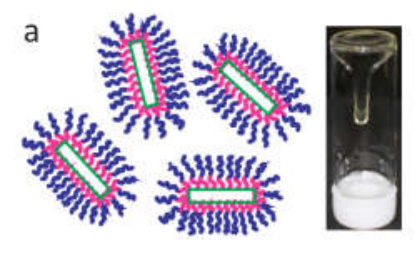

Poli
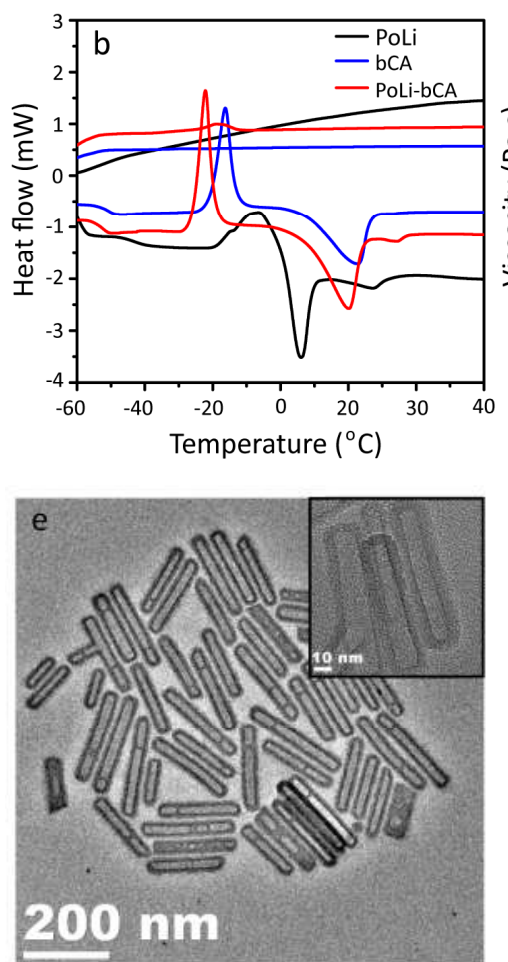

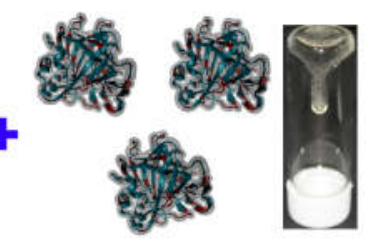

bCA
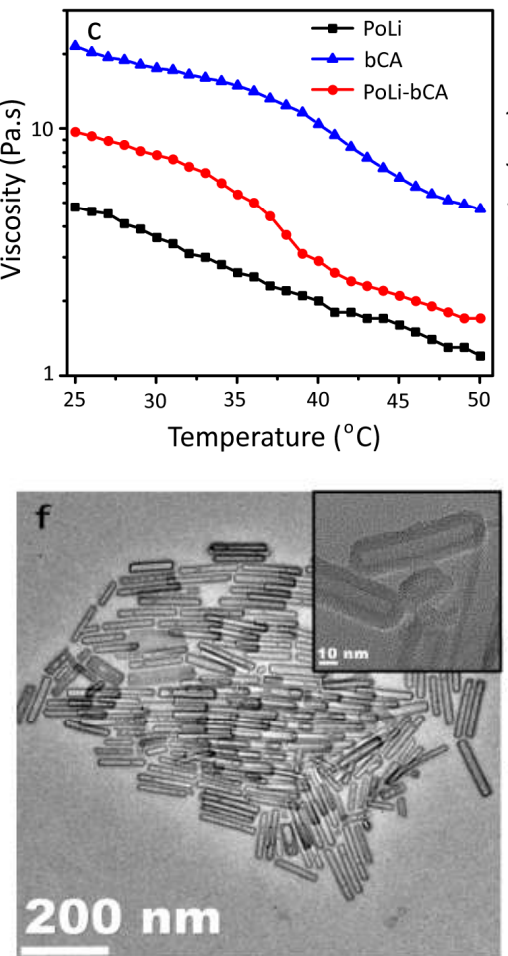

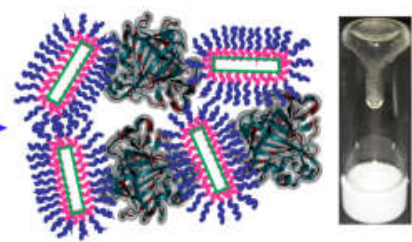

PoLi-bCA
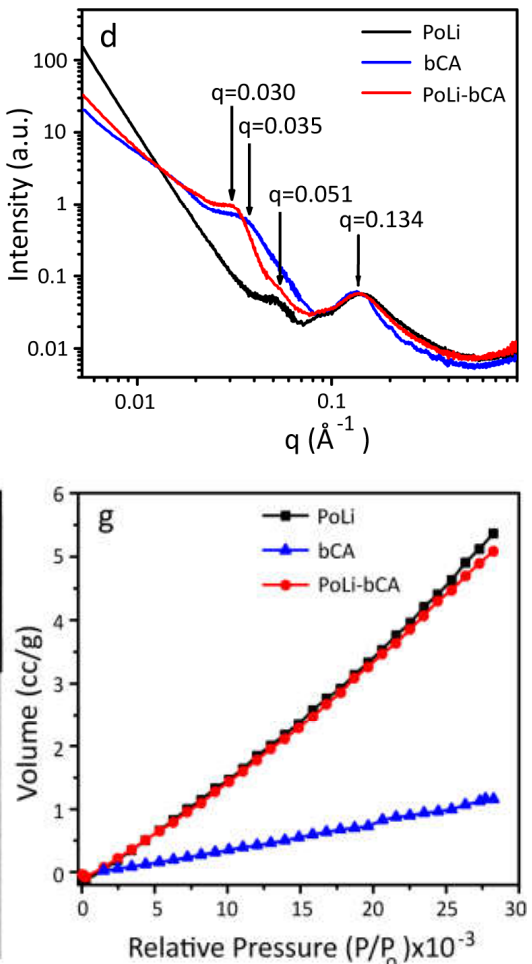

Figure 1. (a) Schematic representation of the method of fabrication of solvent-less porous liquid composite PoLi-bCA by mixing different core-shell conjugates, polymer-surfactant coated hollow silica nanorods based porous liquid (PoLi) with bioconjugated carbonic anhydrase (bCA; size $5.3 \mathrm{~nm}$ ) in a solution at 1:50 number ratio, followed by lyophilization and heating at $60^{\circ} \mathrm{C}$. The solvent-free composite had intact silica rods (TEM) with welldefined amorphous shells (HRTEM, top inset), and shows liquid-like flow behavior (snapshot of PoLi-bCA sample vial, bottom inset); (b) DSC of PoLi, bCA, PoLi-bCA showing endothermic melting, exothermic crystallization, temperatures, respectively, and a second order glass transition temperature; (c) Temperature sweep rheology experiment performed from $25{ }^{\circ} \mathrm{C}$ to $50{ }^{\circ} \mathrm{C}$ at constant shear rate of $1 \mathrm{~s}^{-1}$ providing viscosities of PoLi, bCA and PoLi-bCA (d) $\mathrm{CO}_{2}$ adsorption profile of PoLi, bCA and PoLi-bCA at $0.03 P / P_{o}$. 

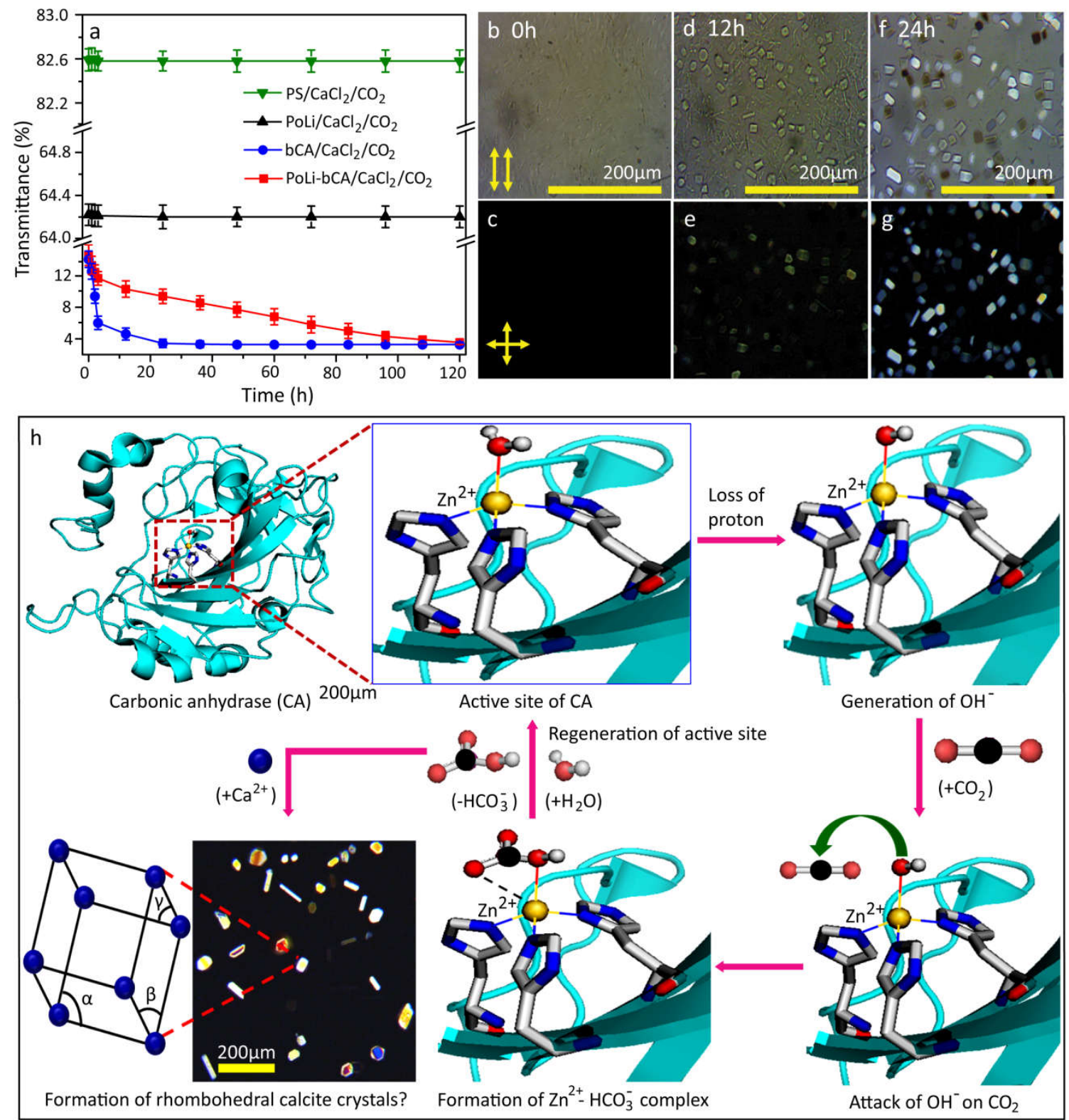

Figure 2. UV-Vis transmittance and bright-field POM studies (a-g): (a) Time-dependent transmittance spectra of $\mathrm{PS} / \mathrm{CaCl} 2, \mathrm{PoLi} / \mathrm{CaCl}_{2}, \mathrm{PoLi}-\mathrm{bCA} / \mathrm{CaCl}_{2}$, bCA $/ \mathrm{CaCl}_{2}$ obtained after passing $\mathrm{CO}_{2}$ in all samples for $3 \mathrm{~h}$ at room temperature, shows a decrease in transmittance for the bCA containing samples due to conversion of $\mathrm{CO}_{2}$ to $\mathrm{CaCO}_{3}$ crystals; $(b, c)$ Bright-field parallel and crossed POM images of PoLi-bCA/CaCl 2 (control, i.e. before passing $\mathrm{CO}_{2}$ ) respectively, (at $30{ }^{\circ} \mathrm{C}$ ); (d-g) Time-dependent bright-field parallel and crossed POM images of PoLi-bCA $/ \mathrm{CaCl}_{2}$ recorded at $30^{\circ} \mathrm{C}$ after (d, e) $12 \mathrm{~h}$ and (f, g) $24 \mathrm{~h}$ respectively, of passing $\mathrm{CO}_{2}$, showed the formation of micron-sized pseudo-cubical along with rod-like crystals. The average dimensions of the crystals grew over $24 \mathrm{~h}$. Mechanism of carbonic anhydrase conversion of $\mathrm{CO}_{2}$ to carbonate $(\mathrm{h}):^{35,36} \mathrm{VMD}$ representation of the active site of bovine carbonic anhydrase (PDB file: 1V9E) comprising of $\mathrm{Zn}^{2+}$ metal ion surrounded by three histidine residues (His 93, His 95 and His 118) and one $\mathrm{H}_{2} \mathrm{O}$ molecule. 

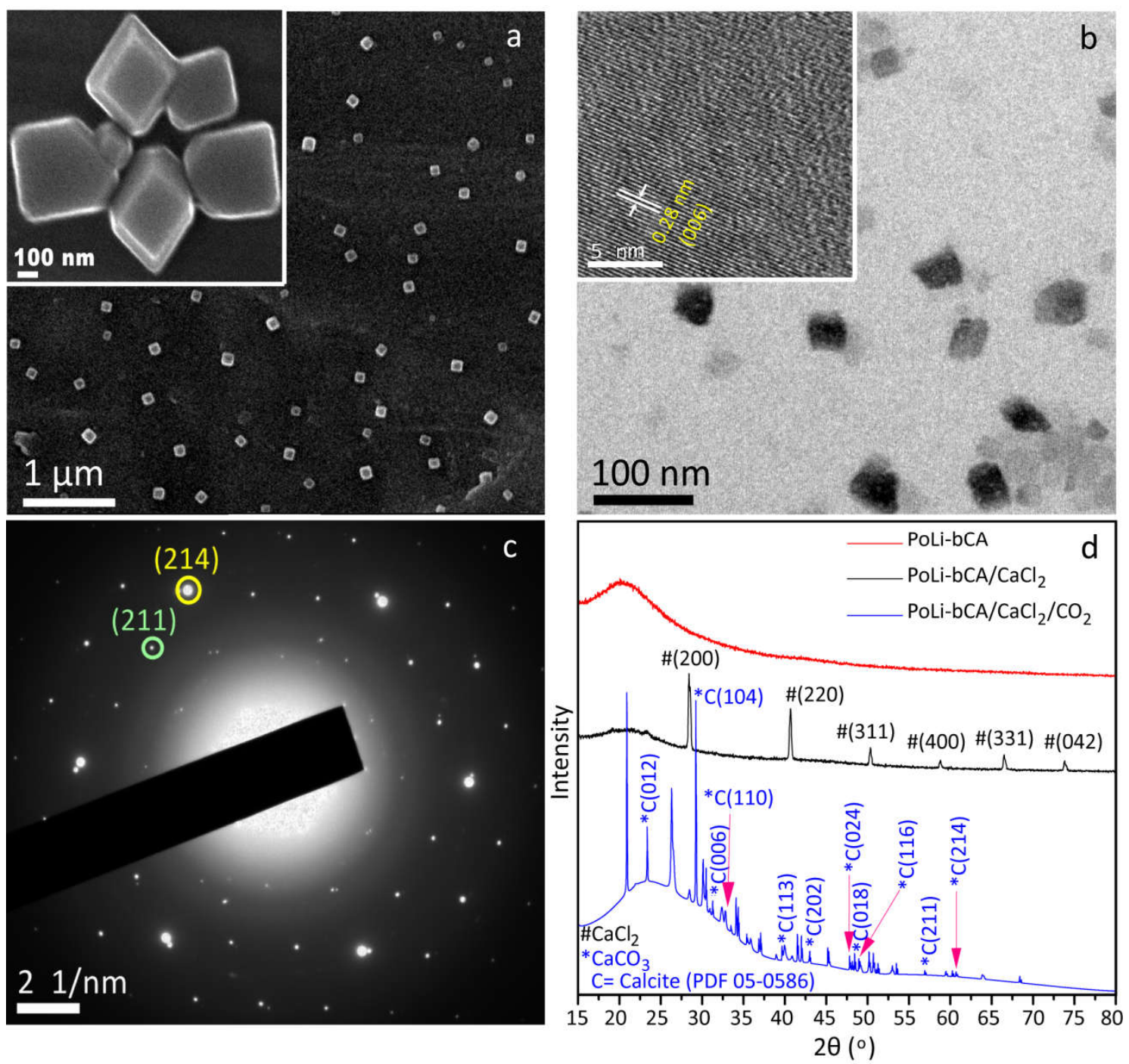

Figure 3. (a) SEM image of PoLi-bCA/CaCl $/ \mathrm{CO}_{2}$ sample showing the formation of quasicubical crystals of dimension $\approx 115 \times 103 \mathrm{~nm}$ (inset, Figure 3a represents bigger crystals with dimension ca. $350 \times 305 \mathrm{~nm}$ ); (b) TEM image of crystals centrifuged from the same sample showingdimensions of $\approx 40 \times 33 \mathrm{~nm}$ (inset, Figure $3 \mathrm{~b}$ shows the HRTEM image of a quasicubical crystal having lattice spacing of $0.28 \mathrm{~nm}$ corresponding to (006) plane of $\mathrm{CaCO}_{3}$ calcite crystal); (c) Characteristic SAED pattern of crystals seen in TEM indicating the presence of lattice planes (211) and (214) corresponding to $\mathrm{CaCO}_{3}$ calcite crystal; (d) XRD pattern of crystals centrifuged from PoLi-bCA/CaCl$/ \mathrm{CO}_{2}$ showing the presence of peaks corresponding to $\mathrm{CaCO}_{3}$ calcite crystals; control samples show absence of these. 

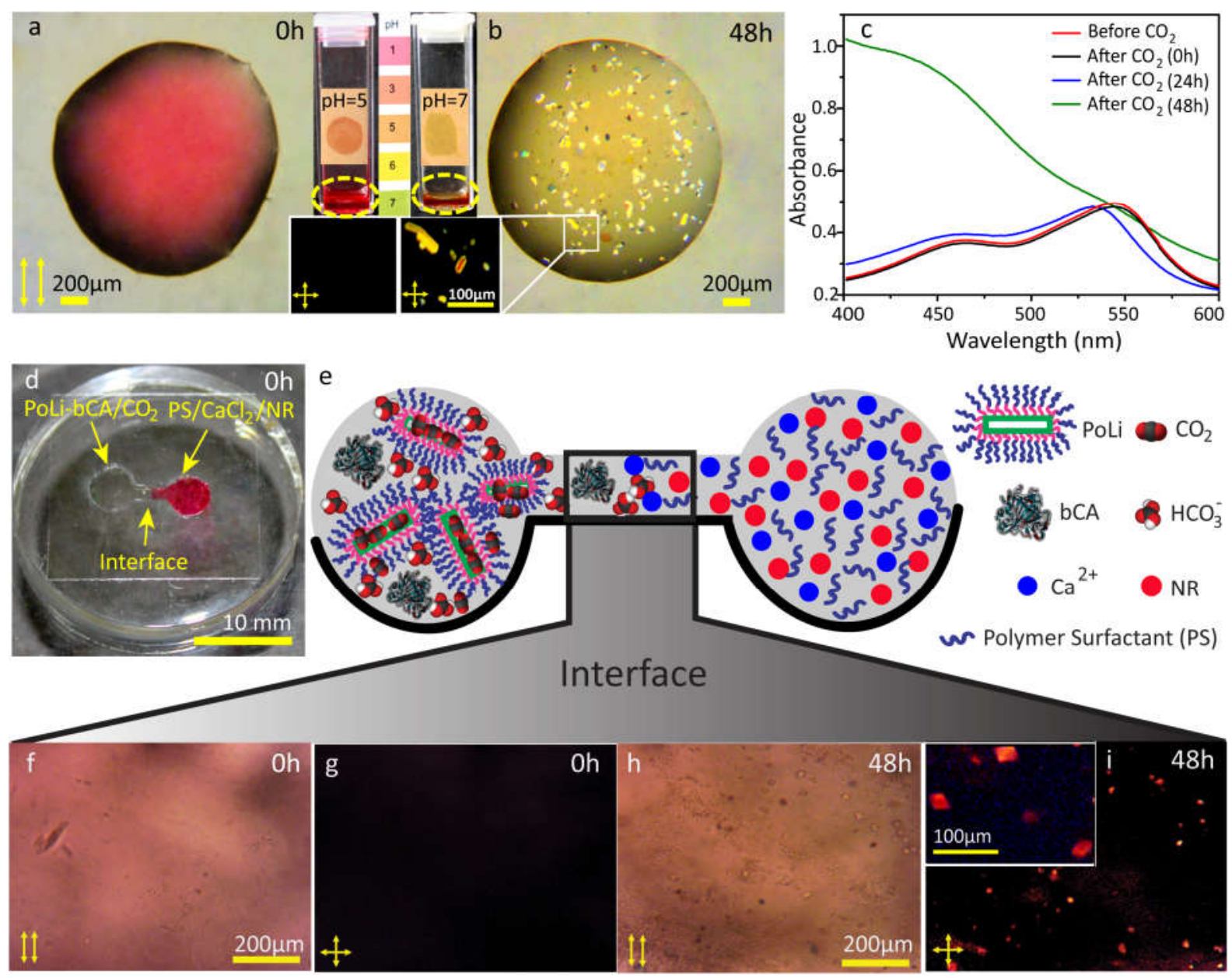

Figure 4. $(\mathrm{a}, \mathrm{b})$ Bright-field parallel POM image of a droplet of PoLi-bCA/CaCl $/ \mathrm{NR} / \mathrm{CO}_{2}$ sample (a) at $0 \mathrm{~h}$ and (b) after $48 \mathrm{~h}$, showing color transition of neutral red (NR) dye from red to yellow due to change in $\mathrm{pH}$ from 5 to 7 (inset, Figure $4(\mathrm{a}, \mathrm{b})$ represent the corresponding cross POM image, where after $48 \mathrm{~h}$ the formation of $\mathrm{CaCO}_{3}$ crystals can be observed). Top, inset, Figure $4(\mathrm{a}, \mathrm{b})$ shows snapshot of litmus paper and the associated $\mathrm{pH}$ difference between a drop of PoLi-bCA/CaCl$/ 2 / \mathrm{NR} / \mathrm{CO}_{2}$ at $0 \mathrm{~h}(\mathrm{pH} \approx 5)$ and after $48 \mathrm{~h}(\mathrm{pH} \approx 7)$, respectively, due to formation of $\mathrm{CaCO}_{3}$ crystals (standard $\mathrm{pH}$ color code bar also shown in the inset to identify $\mathrm{pH}$ transitions); (c) UV-visible spectra of PoLi-bCA/CaCl$/ 2 / \mathrm{NR}$ before and after passing $\mathrm{CO}_{2}$ at different time interval ( $0 \mathrm{~h}, 24 \mathrm{~h}$ and $\left.48 \mathrm{~h}\right)$; (d) Snapshot of a PDMS disk having two hemispherical compartments connected with each other by a narrow slit forming the interface. (e) Scheme shows that right compartment contains a mixture of polymer surfactant (PS), $\mathrm{CaCl}_{2}(0.01 \% \mathrm{w} / \mathrm{w}$ of PS) and NR dye $(0.001 \% \mathrm{w} / \mathrm{w}$ of PS), whereas the left compartment comprises of PoLi-bCA/ $\mathrm{CO}_{2}$. (f-i) Bright-field parallel and crosspolarised images of the interface at $(\mathrm{f}, \mathrm{g}) 0 \mathrm{~h}$ and $(\mathrm{h}, \mathrm{i}) 48 \mathrm{~h}$ (inset, Figure 4ishows the corresponding cross-polarised image at higher magnification) Comparison of $0 \mathrm{~h}$ and $48 \mathrm{~h}$ images indicate a slight colour change and the simultaneous formation of $\mathrm{CaCO}_{3}$ crystals 